\title{
Relaionship between Employee-Organization Congruence (perceived) and Organizational Commitment in the Sri Lankan Apparel Sector
}

\author{
G.D.N.Perera ${ }^{1}$
}

${ }^{1}$ Senior Lecturer, Department of Human Resource Management, University of Sri Jayewardenapura, Sri Lanka

\begin{abstract}
The objective of this research paper was to investigate the relationship between perceived Employee-Organization congruence $(E O C)$ and Organizational Commitment (OC) in the Sri Lankan apparel sector. The present study, which was part of a comprehensive study Employee-Organization congruence (EOC) and attitudes, empirically evaluated seven perceived EOC related factors that could have effect on EOC namely supportiveness, innovation, aggressiveness, attention to detail, outcome orientation, emphasis on rewards, team orientation and three OC factors, that is affective, normative and effective commitments. The study involved 175 machine operators who were selected from 05 large garment factories in Sri Lanka. The results indicated that all the EOC variables were positively and significantly correlated to OC. This study would be an effective contribution in the existing body of knowledge. Human Resource Managers and other recruiters may be helped to recognize the significance of perceived EOC and $O C$ as well as their relationship with each other for ensuring selection of machine operators. Perceived congruence in the organization, will help creating and maintaining a conducive environment for improving organizational commitment of the machine operators which will ultimately result in enhanced efficacy and effectiveness of the organization.
\end{abstract}

Keywords: Employee Organization Congruence, Organizational Commitment, Factory Workers, Apparel Sector, Sri Lanka JEL Classification Code: L16; L67

\section{INTRODUCTION}

$\mathrm{T}^{\mathrm{r}}$ HE success and effectiveness of an organization depends upon many factors. For an organization's competitive advantage, it is inevitable to have talented and loyal employees (Dawley, et al., 2010).Researchers are focusing on employees work related attitudes and the factors that shape these attitudes. In this context, Employee - Organization Congruence (EOC) is a phenomenon that has considerable impact upon employee's commitment and ultimately organization's success. Similarly, the congruence between the employee and the organization has been related to various attitudinal and behavioral outcomes such as job satisfaction, organizational commitment, intention to quit and turnover (Brown, et al., 2005; Hoffman and Woehr, 2006; Wheeler, et al., 2007). Sufficient empirical support is there for the notion that is Employee - Organization Congruence is an important predictor of positive work-related attitudes (Brown et al., 2005).EOC is generally defined as the compatibility between employees and the organizations where they work (Sekiguchi,2003). Specifically, EOC refers to the states of resemblance between the employee's value and the perceived organizational values. However, empirical research demonstrated that EOC has a strong bearing on organizational outcomes, and it has been proved to be strong determinants for persons' attraction to, selection by and retention in the organizations (Schneider, et al.2000). In Sri Lankan context, it is still an elusive phenomenon lacking in research.
Along with this, organizational commitment is also linked with EOC. Organizational commitment which refers to employees' acceptance, involvement and dedication toward achieving organization's goals and keeping membership with the organization, is a vital factor behind the success of any organization as it increases retention rate, reduces operating cost for recruitment and makes employees committed, hard working and punctual (Jain,et al.,2009).

Most EOC studies have been conducted in Western countries and samples included mainly university, post graduates and public sector employees (Garavan, 2007; O'Reilly,et al.1991). Research on EOC in non Western countries are limited. This reason motivated to the researcher to conduct the empirical investigation in non-western context. It helps to fill the gap between employee characteristics and organizational characteristics of apparel sector by testing employee values as predictors of commitment in Asian countries. The present study therefore aims to investigate the relationship among Employee - Organization Congruence and Organizational Commitment.

\section{REVIEW OF LITERATURE}

The concept of Person-environment congruence(P-E) is grounded in the interactions' theory of behavior (Ambrose, et al.2008; Edward and Cable, 2009).The interactions' theory perspective is a theoretical tradition, that begins with Lewin's(1951) propositions that the human behavior is a func- 
tion of the person and environment. That is P-E congruence can be explained as the interaction between the individual characteristics (psychological needs, personality traits, person factors) and the organizational or situational characteristics (nature of rewards, cultural value and environmentalcondition).Person-environment congruence is defined as the degree of congruence or match between personal and situational variables in producing significant selected outcomes (Muchinsky and Monahan, 1987). Many researchers have used P-E congruence approach to identify the congruence between individual characteristics and organizational characteristics (Ambrose, et al.2008; Edward and Cable, 2009; Edwards et al. 2008). P-E congruence can be conceptualized with various congruence dimensions including an individual's congruence with a job (person-job), congruence with a group (person-group), congruence with a vocation (person-vocation) and congruence with an organization (person-organization) (Caldwell et al.2004; Cooper et al.2004;Jansen and Kristof-Brown, 2006; O'Reilly, et al.1991; Schneider, 2001).Person-organization congruence is embedded in the broader concept of person-environment congruence. Therefore, this study provides more attention to the employee -organization congruence (EOC). Perceived congruence is an indirect measure where employees are asked to describe both their own personal values and their organizational values (Bowen, et al.1991; Edward, et al.2008). Considering previous researchers comments, this study operationalizes EOC using values with the organizational culture profile. Organizational culture profile (OCP) developed by O'Reilly, et al. (1991) to measure EOC (Carlson and Herdman, 2005; Hamdan, 2011; Nazir, 2005; Shar, et al.2009).OCP had been revised twice since 1991.This study considered the revised version (see table 1 ).

Organizational commitment is the employee's willingness to extend effort in order to achieve the organizational goals and the degree of alignment between the organization goals and values of the employee (Mowday, et al.1982). Organizational commitment consists of different types and each type influences on the job behavior differently (Meyer and Allen, 1991).Organizational commitment refers to the extent to which an employee develops an attachment and feels a sense of allegiance to his or her employer (The Pennsylvania State University, 2011).

TABLE 1

ORGANIZATIONAL CULTURE PROFILE (OCP)

\begin{tabular}{|l|l|}
\hline $\begin{array}{l}\text { Elements of the original ver- } \\
\text { sion }\end{array}$ & $\begin{array}{l}\text { Elements of the revised } \\
\text { version }\end{array}$ \\
\hline Innovation and risk taking & Supportiveness \\
\hline Aggressiveness & Innovation \\
\hline Attention to detail & Aggressiveness \\
\hline Orientation towards outcomes & Attention to detail \\
\hline Supportiveness & Outcome orientation \\
\hline Team orientation & Emphasis on rewards \\
\hline $\begin{array}{l}\text { Emphasis of growth and re- } \\
\text { wards }\end{array}$ & Team orientation \\
\hline Derd
\end{tabular}

Decisiveness

Source:( Charles, et al. 1991)
There are different models available on organizational commitment, namely, Steers model, (1977) and Allen and Meyer model (1990) (Addae, et al.2008; Brigham, 2007; Greeberg, et al.2005). Allen and Meyer model explained three types of commitment, namely, affective commitment (employee's feelings of loyalty to organization because he or she believes in the organization), normative commitment (refers to employee feelings about to stay with the organization because the costs of leaving are too great) and continuance commitment (refers a feeling of obligation to stay in the organization and continue employment) (Addae, et al.2008; Arumugam,2006;Boon and Meyer, et al.2010).

This study considers the Allen and Meyer model, that is related to affective, normative and continuance commitment and the EOC.EOC meets employees' personal values and organizational values to achieve the organizational commitment. This leads to higher level of organizational commitment to the worker with more positive values (individual and organizational).

\section{RESEARCH METHOD}

\section{Study design}

This study was interested in investigating whether there is a relationship between EOC and OC, rather than establishing definite cause $\rightarrow$ effect relationship among variables. Hence, the type of investigation of this study is co relational rather than causal. For the purpose of the collection of the data on which this study was based largely in order to achieve objectives of the study, a structured questionnaire was used.

The present study was descriptive in nature. Quantitative approach and survey research design used. Hence, the researcher interference on normal flow of events was minimal. This study is conducted in apparel sector in Sri Lanka. The population of the study comprise of the machine operators of apparel sector. Simple random sampling technique is used to select the representative sample of the population. The actual sample size is 175 whereas 160 completed surveys have been received (i.e. a response rate of $91 \%$ ). Since the unit of analysis of this study was machine operators, the data were collected by giving questionnaires with an envelope. A letter of questionnaire and letter of appreciation were attached to the questionnaire. They consisted with self-introduction of the researcher, the reason for conducting the research and assurance of security of the information given by the respondent.

\section{Instruments:}

Two research instruments were used to collect data. Perceived congruence was assessed using the organizational culture profile (OCP) instrument (O'Reilly,et al.1991). Congruence was assessed using seven dimensions item regarding Organization Characteristics and Individual preference. Congruence was operationalized as the sum of the differences between responses to corresponding items on the two scales using a 5-point Likert-type scale; 1 = strongly disa- 
greed to 5 strongly agreed. Organizational commitment inventory by Mayer \& Allen (1997) was used as a research instrument, comprised of 15 items constructed on 5 point scale. Scoring criterion of the items was in a way that higher scores indicated higher level of EOC and OC. Data were collected through personal visits by the researcher to the sample organizations. Responses were analyzed statistically through SPSS 16 by using correlation and regression.

\section{RESULTS AND DISCUSSION}

The results of the study are explained below.

TABLE 2: CORRELATION MATRIX OF RELATIONSHIP BETWEEN EMPLOYEE - ORGANIZATION CONGRUENCE AND ORGANIZATION COMMITMENT (AFFECTIVE, NORMATIVE, CONTINUOUS)

\begin{tabular}{|l|l|l|l|l|l|}
\hline Variable & 1 & 2 & 3 & 4 & 5 \\
\hline $\begin{array}{l}\text { Affective } \\
\text { commitment }\end{array}$ & 1.000 & & & & \\
\hline $\begin{array}{l}\text { Normative } \\
\text { commitment }\end{array}$ & 0.850 & 1.000 & & & \\
\hline $\begin{array}{l}\text { Continuous } \\
\text { commitment }\end{array}$ & 0.950 & 0.930 & 1.000 & & \\
\hline O commitment & 0.984 & 0.974 & 0.945 & 1.000 & \\
\hline $\begin{array}{l}\text { Employee- } \\
\text { organization } \\
\text { congruence }\end{array}$ & 0.796 & 0.892 & 0.880 & 0.788 & 1.000 \\
\hline
\end{tabular}

${ }^{* *}$ Correlation is significant at the 0.01 level (2-tailed).

The statistical analysis given at table 2 above support the relationship between EOC and OC. Employeeorganization congruence has a significant positive relationship with Organizational Commitment. $(\mathrm{r}=0.788$, $\mathrm{p}<.01)$. The coefficient correlation $(\mathrm{r}=.788)$ indicates high positive correlation between these two variable.

The findings of the study indicated that Employee- Organization Congruence and Organizational Commitment have positive relationship with each other. Employee- Organization Congruence is a strong predictor of Organizational Commitment and as Organizational Commitment is a highly influential variable leading towards numerous positive outcomes for the organization (Khan et al. 2010). It is therefore necessary that apparel sector in Sri Lanka should attract and retain factory workers whose personal values are best matched with organizational values, this high level of employee- organization congruence will be helpful for creating and maintaining conducive environment for improving organizational commitment which will ultimately lead towards enhanced effectiveness of these organizations.

\section{CONCLUSION}

The present study analyzed the relationship among, employee-organization congruence and organizational commitment. The analyzed data revealed a positive relationship between employee-organization congruence and organizational commitment. This relationship was found to be significant as well. It was revealed that employee- organization congruence is a strong predictor of organizational commitment. In conclusion, organizations should adopt the policies and practices that ensure recruitment and retention of the employees with high level of employee-organization congruence so that organizational commitment can be ensured.

\section{LIMITATIONS AND FUTURE RESEARCH:}

This study was limited to single sector. Other service sectors such as hospitals, banks etc. should be focused by future researchers so that some common model for service sector regarding Employee-Organization Congruence and Organizational Commitment can be proposed. Future research can also be conducted to find out the contributing factors of these variables.

\section{REFERENCES}

[1] Addae, H.M., Parboteeah, K.P. and Velinor.N.(2008).Role stressors and organizational commitment :Public sector employment in St.Lucia.International journal of manpower,29(6),567-582.

[2] Ambrose, M. L., Arnaud, A., \& Schminke, M. (2008). Individual Moral Development and Ethical Climate: Theinfluence of PersonOrganization Fit on Job Attitudes. Journal of Business Ethics, 77, 323333.http://dx.doi.org/10.1007/s10551-007-9352-1.

[3] Brown, A. L., Zimmerman, R. D. \& Johnson, E. C. (2005). Consequences of individuals' fit at work: A meta-analysis of person-job, person-organization, person-group, and person-supervisor fit. Personnel Psychology, 58, 281-342.

[4] Carlson,K.D. and Herdman,A.O.(2005).Measures of person work environment fit constructs:conceptual ambiguity and empirical reality.Presented at the 65th Annual meeting of the Academy of Management,Hawaii.

[5] Coldwell, D., Billberry, J., Van Meurs, N. \& Marsh, P. (2004). The effect of person organization fit on employee attraction and retention; towards a testable, explanatory model; workforce and retention study. Planning Institute of Australia (SA Division), 87-117.

[6] Dawley. D. D., Andrews M. C. \& Bucklew, N. S. (2010). Enhancing the ties that bind: mentoring as a moderator. Career Development International, 15(3), 259-278.

[7] Edwards, B.D., Bell.S.T. , Arthur. W. and Decuir. A.D. (2008).Relationships between facets job satisfaction, task, and contextual performance. Applied Psychology. An International Review, 57, 3, $441-465$.

[8] Edwards, J.R and Cable, D.M.(2009).The value of value congruence. Journal of Applied Psychology.94 (3).654-677.

[9] Hamdan,M.H.(2011).Mediators of the relationship between personorganization fit and outcome. School of management, faculty of business, Queensland University of Technology, Australia.

[10] Hoffman, B. J. \& Woehr, D. J. (2006). A quantitative review of the relationship between person-organization fit and behavioral outcomes. Journal of Vocational Behavior, 68, 389-399.

[11] Jansen,K. and Kristof-Brown.A.(2006).Toward a multi dimensional theory of person- environment fit. Journal of Managerial Issues.28.193-212.

[12] Lewin.K.(1935).Dynamic theory of personality, New York: MoGraw -Hill.

[13] Meyer, J. P., \& Allen, N. J. (1991). A three component conceptualization of organizational commitment. Human Resource Management Review, 1, 61-89. 
[14] Mowday; R. T. Steers, R. M., and Porter, L. W.(1982) "The Measurement of Organizational Commitment", Journal of Vocational Behavior, Vol.14, pp.224-227.

[15] Muchinsky, P. M., \& Monahan, C. J. (1987). What is personenvironment congruence? Supplementary versus complementary models of fit. Journal of Vocational Behavior, 31, 268-277.

[16] O'Reilly III, C.A, Chatman, J. \& Caldwell, D.F. (1991). People and organizational culture: A profile comparison approach to assessing personorganization fit. Academy of Management Journal, 34, 487-516.

[17] Sekiguchi, T. (2003). A contingency perspective on the importance of P$\mathrm{J}$ fit and $\mathrm{P}-\mathrm{O}$ fit in employee selection. Paper presented at the Annual
Conference of Academy of Management, Seattle, WA.

[18] The Pennsylvania State University (2011). Lesson 12: Work and organizational commitment: Introduction to Work and Organizational Commitment. Retrieved from Lecture Notes Online Web site https://cms.psu.edu/section/content/default.asp?WCI=pgDisplay\&W CU=CRSCNT\&ENTRY_ID=97D4659902F4475D805509F12683C53D

[19] Wheeler, A. R., Gallagher, V. C. Brouer, R. L. \& Sablynski, C. J. (2007). When person-organization (mis)fit and (dis)satisfaction lead to turnover: The moderating role of perceived job mobility. Journal of Managerial Psychology, 22(2), 203-219.

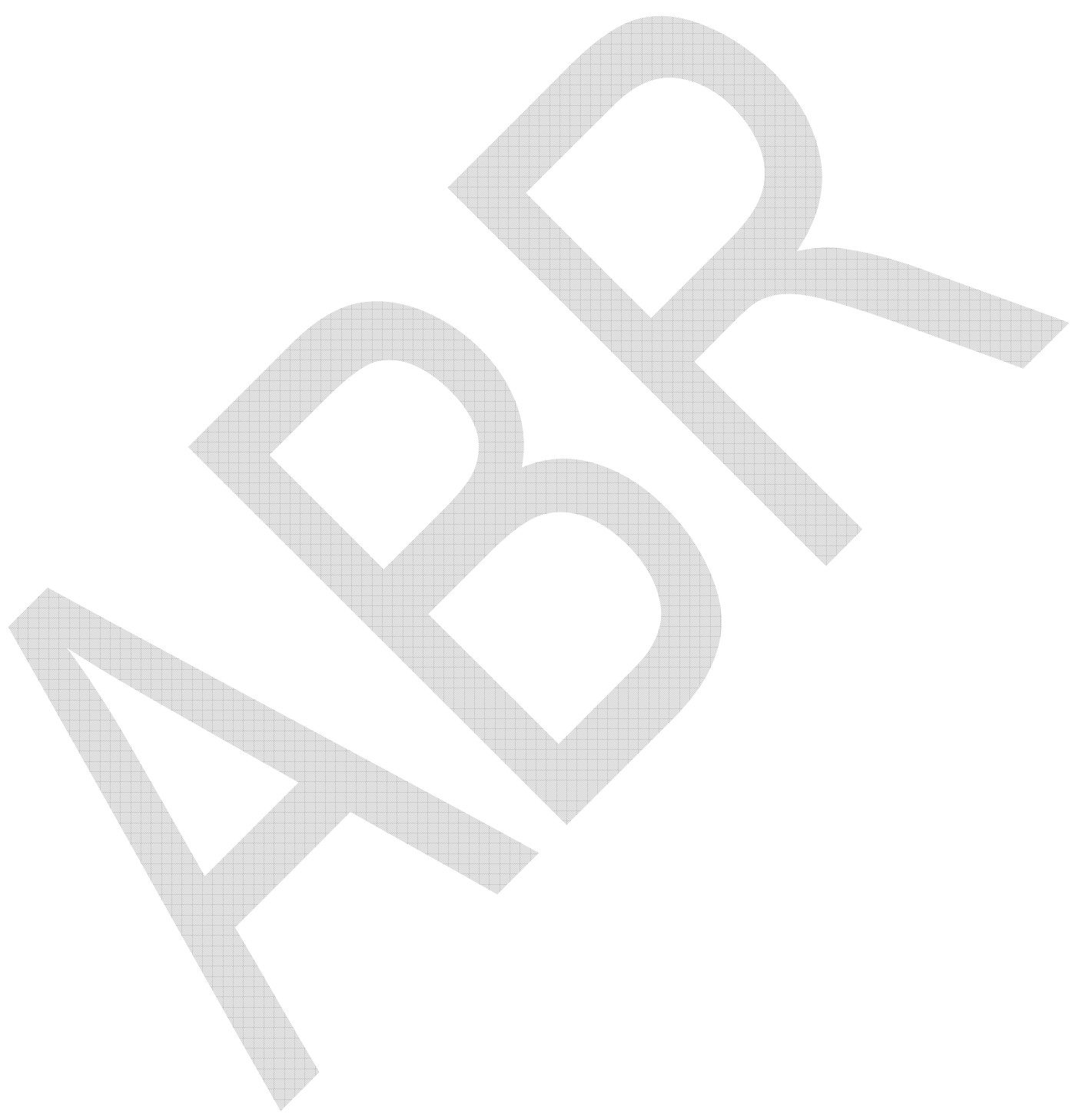

